\title{
Transverse Crack Modeling and Validation in Rotor Systems, Including Thermal Effects
}

\author{
N. Bachschmid, P. Pennacchi, and E. Tanzi \\ Dipartimento di Meccanica, Politecnico di Milano, Milan, Italy \\ S. Audebert \\ Recherche et Développement, Département Acoustique et Mécanique Vibratoire, Electricité de France, \\ Clamart, France
}

This article describes a model that allows the simulation of the static behavior of a transverse crack in a horizontal rotor under the action of weight and other possible static loads and the dynamic behavior of cracked rotating shaft. The crack breathes-that is, the mechanism of the crack's opening and closing is ruled by the stress on the cracked section exerted by the external loads. In a rotor, the stresses are time-dependent and have a period equal to the period of rotation; thus, the crack periodically breathes. An original, simplified model allows cracks of various shapes to be modeled and thermal stresses to be taken into account, as they may influence the opening and closing mechanism. The proposed method was validated by using two criteria. First the crack's breathing mechanism, simulated by the model, was compared with the results obtained by a nonlinear, threedimensional finite element model calculation, and a good agreement in the results was observed. Then the proposed model allowed the development of the equivalent cracked beam. The results of this model were compared with those obtained by the three-dimensional finite element model. Also in this case, there was a good agreement in the results.

Therefore, the proposed models of the crack and the equivalent model of the beam can be inserted into the finite element model of the beam used for the rotor's dynamicbehavior simulation; the obtained equations have timedependent coefficients, but they can be integrated into the frequency domain by using the harmonic balance method.

Received 28 March 2002; accepted 28 March 2002.

This work was partially funded by the MURST (Italian Ministry for the University and Scientific Research) Cofinanziamento Identificazione di Malfunzionamenti in Sistemi Meccanici for the year 1999.

Address correspondence to Nicolò Bachschmid, Dipartimento di Meccanica, Politecnico di Milano, Via La Masa 34, I-20158 Milano, Italy. E-mail: nicolo.bachschmid@ polimi.it
The model is suitable for finite beam elements with 6 degrees of freedom per node in order to account also for torsion vibrations and coupling between torsion and flexural vibrations.

Keywords breathing effect, crack modeling, rotordynamics, thermal transient, transverse crack

The description of the dynamic behavior of a horizontal heavy rotor that presents a transverse crack has been presented by many researchers (e.g., Dimarogonas 1996; Gasch 1993; and Wauer 1990), particularly as regards the breathing mechanism. This characteristic behavior takes place during the rotor's rotation; the crack moves from the upper position, in which the static bending moment forces the crack to be closed to the opposite position in which the crack is forced to be open. The gradual opening and closing of the crack is called the breathing mechanism. Therefore, the stiffness changes periodically during one rotation and, correspondingly, so does the static deflection due to the weight (and to the bearing alignment conditions). In fact, the stiffness of a rotor with an open crack is less than that of one with a closed crack, in which the stiffness equals the value of the uncracked shaft. The periodic deflection and the periodic stiffness can be expanded in a Fourier series, of which the most important components are the $1 \times, 2 \times$, and $3 \times$ revolution components. It can be shown that the same forces that excite the static deflection components also excite the dynamic vibrations when the shaft is rotating at higher speeds.

Along with the effect of the static bending moments, thermal transients also have an influence on the breathing mechanism. Often, in real machines, the sudden change in vibrational behavior during thermal transients allowed a crack in the rotating shafts to be discovered. A case history presented by Lapini and colleagues (1993) provides the derivation of Figure 1. It shows the measured vibrations in a bearing of a cracked generator in a 


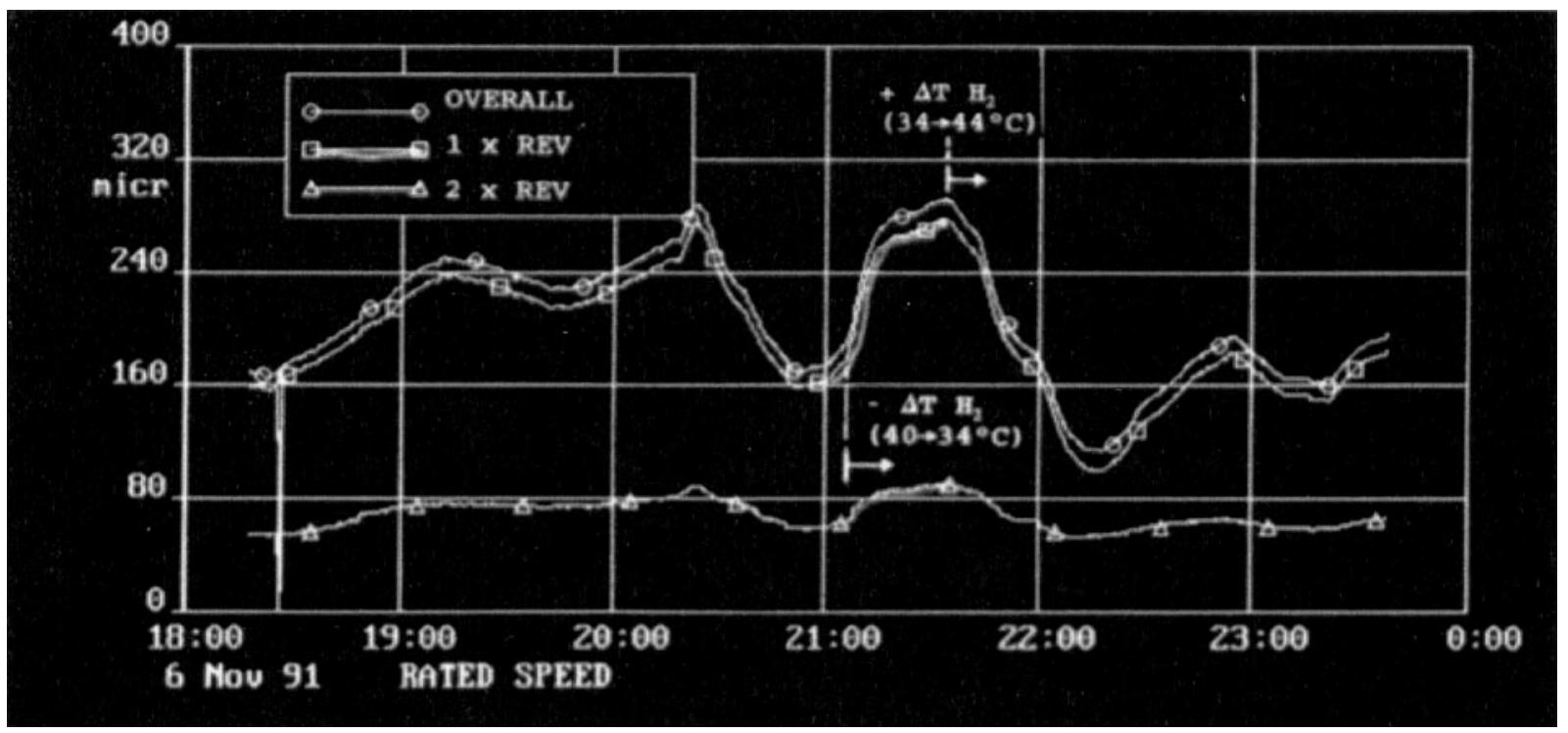

FIGURE 1

Thermal sensitivity of a cracked rotor.

power plant, operating at rated speed due to two thermal transients: first, a cooling in the refrigerating fluid from $40^{\circ} \mathrm{C}$ to $34^{\circ} \mathrm{C}$; then a heating from $34^{\circ} \mathrm{C}$ to $44^{\circ} \mathrm{C}$. During the heating transient (a positive temperature gradient), compressive stresses arise on the skin of the shaft and tensile stresses arise in the core of the shaft. This has following effects.

- If a local bow is present in correspondence with the crack, because of the crack's propagation, the thermal stresses reduce the existing bow, and therefore a reduction in the $1 \times$ revolution vibration component is obtained.

- The thermal stresses tend to prevent and to reduce the breathing behavior, so a reduction of all components $(1 \times, 2 \times$, and $3 \times$ revolution $)$ due to the breathing mechanism is generally obtained.

In the case of a cooling transient (a negative temperature gradient), the opposite situation occurs, with tensile stresses on the skin and compressive stresses on the core. This causes effects on the crack:

- A local bow is generated (or an existing local bow is increased) and the $1 \times$ revolution component of the vibrations due to the unbalance and to the bow is modified.

- The thermal stresses tend to hold the crack open. The breathing mechanism is modified and an increase in the $2 \times$ revolution component is expected.

Previous considerations suggest that a reliable model for the crack's breathing mechanism that also takes into account the effect of thermal transients would be useful. A possible model is described in this article. First, a simplified one-dimension
(1D) model, which was presented by Bachschmid and colleagues (2000), to determine the temperature distribution in a cylindrical rotor is described; then the stiffness changes in the cracked element of the rotor are described by introducing a model with 6 degrees of freedom per mode. The proposed models are validated by comparing the results obtained by performing threedimensional (3D) calculations.

\section{THE THERMAL BEHAVIOR AND BREATHING MECHANISM OF A CRACKED ROTOR}

To determine the temperature distribution, the equation of the thermal exchange is used in the case of axial symmetry and of an infinite cylinder:

$$
\frac{\rho c_{p}}{k} \frac{\partial T}{\partial t}=\frac{1}{r} \frac{\partial}{\partial r} r \frac{\partial T}{\partial r}
$$

where $\rho$ is the density, $c_{p}$ the specific heat, $k$ the conduction coefficient, $r$ the radial coordinate, and $T$ the generic temperature of the section.

To solve the equation, the finite differences were used with two different boundary conditions, depending on the type of heat exchange.

1. In the case of convection on the external surface

$$
\left.\frac{\partial T}{\partial r}\right|_{r_{\text {int }}}=\left.0 \quad k \frac{\partial T}{\partial r}\right|_{r_{e s t}}=H\left(T_{r_{e s t}}-T_{w}\right)
$$

where $H$ is the thermal exchange coefficient between steam or surrounding fluid and metal, $T_{\text {rest }}$ is the temperature of the external surface of the section, and $T_{w}$ is the fluid temperature. 
2. In the case of an imposed temperature gradient $\Delta T / T$ on the external surface.

$$
\left.\frac{\partial T}{\partial r}\right|_{r_{i n t}}=0 \quad T_{r_{e s t}}(t+\Delta t)=T_{r_{e s t}}(t)+\Delta T .
$$

If the number of the discretization points in the finite difference method and the time step $\Delta t$ are fixed, and if the material properties are considered as constant (at the average working temperature), the solving system is of the following type:

$$
\{T(t+\Delta t)\}=[A]\{T(t)\}
$$

where matrix $[A]$ has constant coefficients, and $\{T(t+\Delta t)\}$ and $\{T(t)\}$ are the vectors of the temperatures in the radial coordinates determined over the section. Note that the radial coordinates were chosen in order to divide the section into rings with equal surfaces; therefore, they are thinner close to the external surface.

By iterating Equation (4) with time step $\Delta t$, it is possible to determine the temperature distribution in each point of the section as a function of the time. The axial stress distribution corresponding to the temperature distribution is given by

$$
\sigma=\frac{\alpha E}{1-v}\left(T_{m}-T(r)\right)
$$

where $\alpha$ is the linear thermal expansion, $E$ the Young's modulus, $v$ the Poisson's coefficient, $T(r)$ the temperature at the radial coordinate $r$, and $T_{m}$ the average section temperature. The effect of the centrifugal forces on the axial stresses has been neglected.

The thermal bow is calculated in the following way: the cracked areas in which no contact occurs cannot transmit stresses; therefore, the thermal stress distribution is no longer axial-symmetrical and the resulting moments $M_{B x}$ and $M_{B y}$ of this thermal stress distribution can be calculated with respect to the reference frame, which is fixed to the beam. These moments, with opposite signs, are then applied to both ends of the equiva-

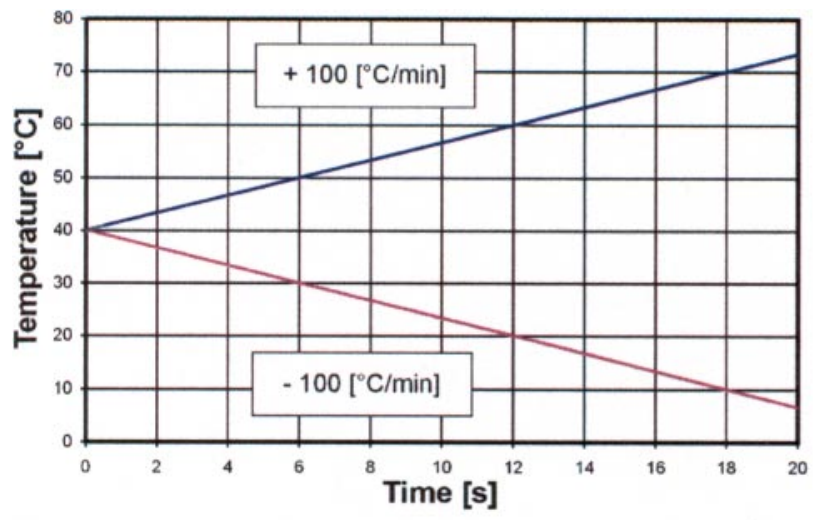

lent beam of length $l_{c}$, which will be defined later, and generate the bow.

This procedure is obviously a rough, approximate approach because the actual stress distribution over the cracked area is completely different from the one assumed by the proposed simplified approach. But it can be assumed that the bow depends on the uncompensated thermal stresses, and the results confirm that the proposed procedure allows estimation of the bow with satisfactory accuracy, as will be shown.

The results obtained are different depending on whether there are short time transients in which the heating or cooling process involves the outer skin of the beam more than the whole body, or whether there are long time transients in which the complete body is affected by the temperature change and also whether high radial strains arise. With respect to the short transients, both the stress distribution around the crack and the deflections are different in long-lasting transients.

\section{NUMERICAL SIMULATIONS}

Some 1D and 3D calculations were made on a round-beam test specimen with a diameter of $25 \mathrm{~mm}$ and a length of $50 \mathrm{~mm}$ that presented a crack with relative depths of $25 \%$ and $50 \%$ of the diameter. Also, mechanical loads were applied to an extension (on the left side) in order to avoid local deformations due to load application. The loads were a bending moment of $10 \mathrm{~nm}$ and a torsion of $25 \mathrm{~nm}$.

Figure 2 shows the skin temperature and the corresponding axial stresses as a function of time for a $\pm 100^{\circ} \mathrm{C} / \mathrm{min}$ temperature gradient, calculated with the 1D model, starting from a uniform temperature distribution of $40^{\circ} \mathrm{C}$.

Figure 3 shows the temperature and the stress distribution over the cross-section of the beam at $5 \mathrm{sec}$ for the $\pm 100^{\circ} \mathrm{C} / \mathrm{min}$ transient.

All these results were obtained with the 1D model, but the actual temperature and stress distributions, obtained by the 3D model in cross-sections that are unaffected by the crack and by the boundary conditions, are quite similar.

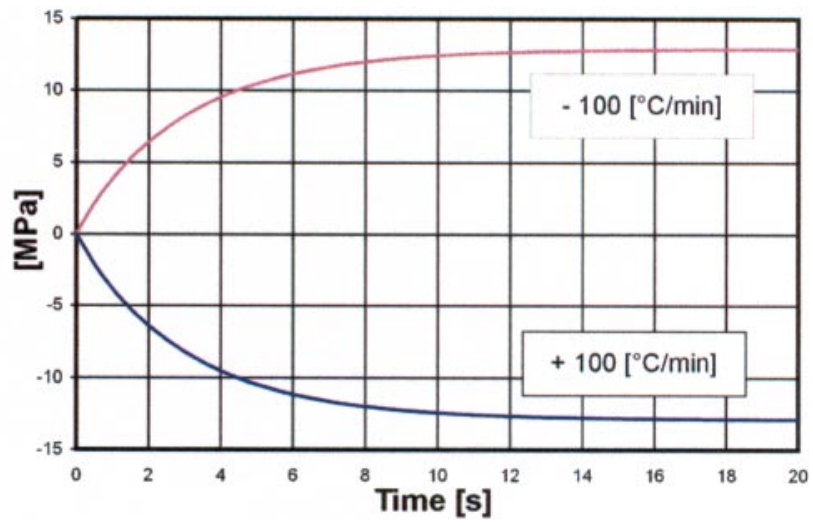

FIGURE 2

Skin temperature (left) and axial stresses (right) for temperature gradient of $\pm 100^{\circ} \mathrm{C} / \mathrm{min}$. 

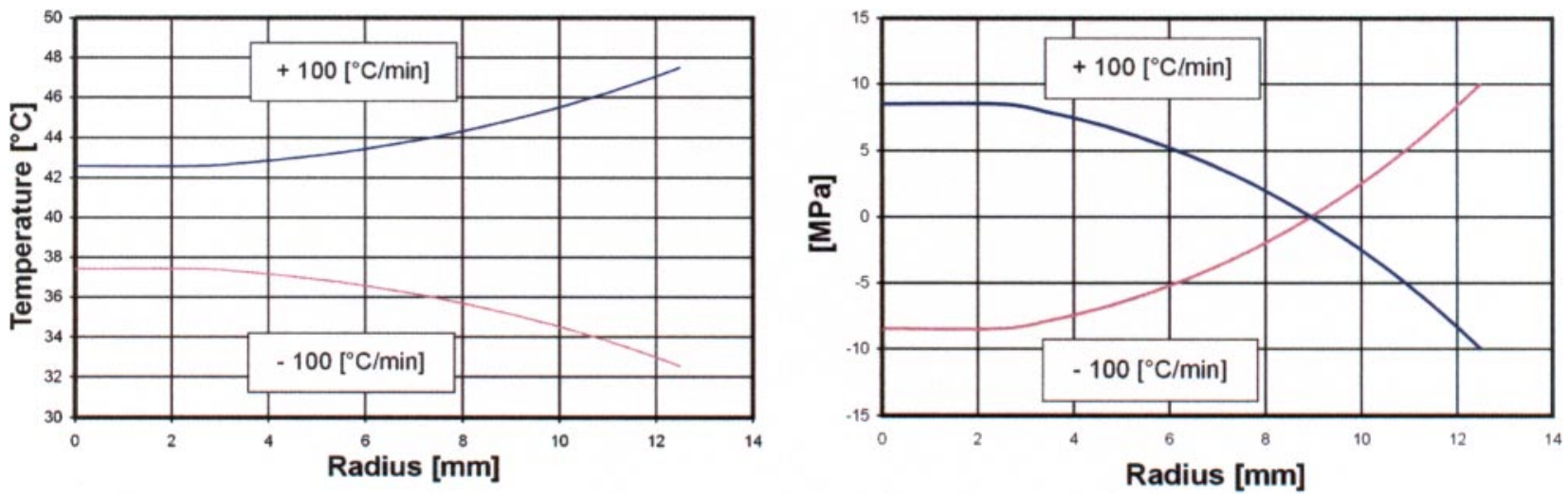

FIGURE 3

Internal temperatures (left) and axial stresses (right) for $\pm 100^{\circ} \mathrm{C} / \mathrm{min}$ gradient at time $5 \mathrm{sec}$.

Figures 4 and 5 show the axial stress distribution on the longitudinal section of the cracked beam, clamped on the right endFigure 4 in the case of a negative sharp transient $\left(-100^{\circ} \mathrm{C} / \mathrm{min}\right.$ in $5 \mathrm{sec}$ ) and Figure 5 in the case of a positive sharp transient $\pm 100^{\circ} \mathrm{C} / \mathrm{min}$ in $5 \mathrm{sec}$ ).

The behavior was as expected: during the negative transient, the positive tensile stresses on the skin and the negative compression stresses on the internal part vanish in correspondence with the crack; the crack is completely open. This can be seen in Figure 6, which shows the relative axial displacements on the crack surface. Only in the dark blue area are the relative displacements vanishing so that some contact can occur. Figure 7 shows the axial stresses on the cracked section. On the cracked surface, the axial stress is roughly 0 ; in the inner part, a maximum compressive stresse of $11.8 \mathrm{MPa}$ is reached; and on the outer part, close to the crack's tip, a maximum tensile stress of $117 \mathrm{MPa}$ is reached. All these figures and some of the following were obtained using the nonlinear 3D model for the crack of $50 \%$ depth.

During the positive transient, the negative compression stresses on the skin remain in correspondence with the crack, but below that small portion, the rest of the crack has no stresses and is therefore open. In correspondence with the crack's tip, very high tensile stress occurs.

Figure 8 shows the stress distribution along the vertical diameter passing through the middle of the crack in the cases of positive and negative transients. This figure shows that the positive temperature transient affects the closure of the crack, as is known from field experience. In fact, in a small area close to the skin, negative compression stresses appear. But very high tensile stresses are generated at the crack's tip (between 110 and $120 \mathrm{MPa}$ ), and they could be responsible for the propagation of the crack in many machines (turbogenerators) in which a slowly propagating crack has been found. This happens then when the rotor is heated during the start-up procedure.

In the simplified model, 1D thermal stresses are simply superposed on stresses arising from mechanical loads; the nonlinear effects cannot be accounted for. Therefore, excellent agreement is found in all parts that are not close to the crack (or to the boundary), but poor agreement is found in the cracked section. Despite this, acceptable agreement was found in the breathing

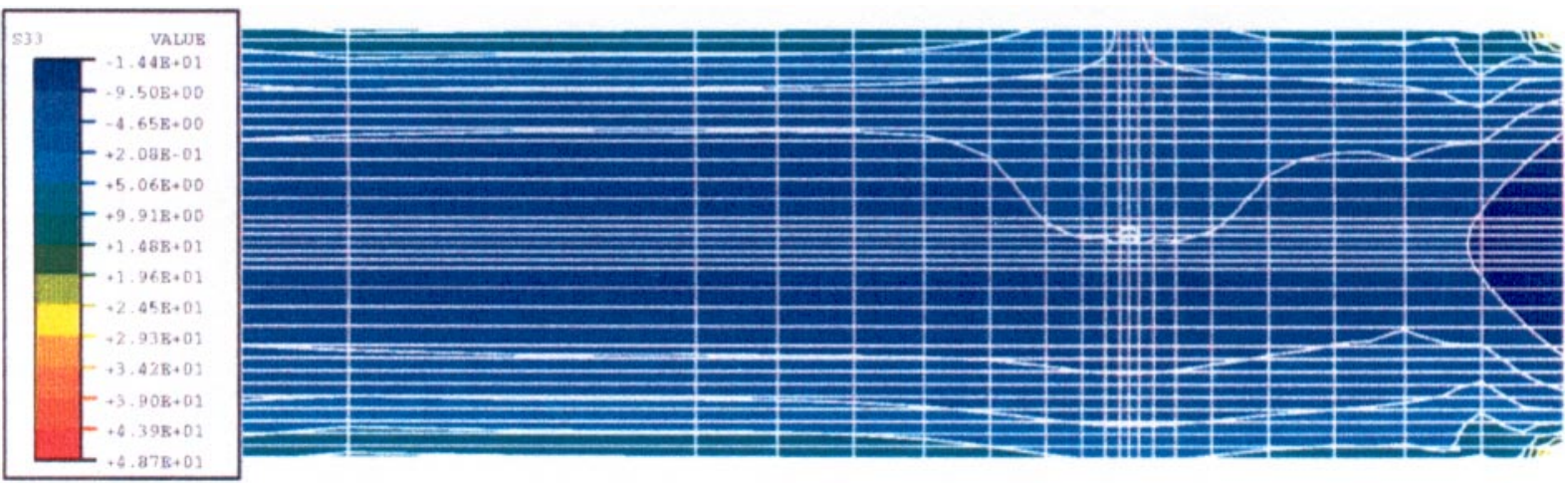

FIGURE 4

Axial stress distribution, cracked beam clamped at right hand side, transient $-100^{\circ} \mathrm{C} / \mathrm{min}, 5 \mathrm{sec}$. 

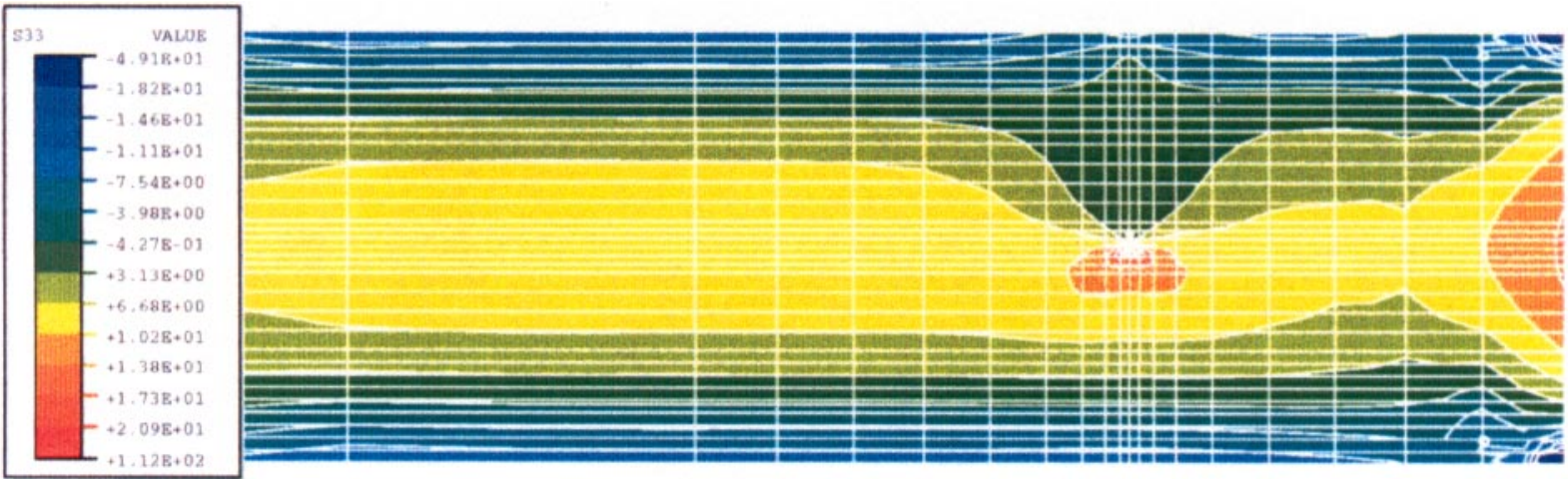

FIGURE 5

Axial stress distribution, cracked beam clamped at right hand side, transient $+100^{\circ} \mathrm{C} / \mathrm{min}, 5 \mathrm{sec}$.

mechanism, as shown hereafter, and a rather good agreement was found in the evaluation of bow due to smooth or sharp temperature transients $\left( \pm 20^{\circ} \mathrm{C} / \mathrm{min}\right.$ and $\left.\pm 100^{\circ} \mathrm{C} / \mathrm{min}\right)$.

The deflections were calculated when the thermal transient was superposed on a mechanical load. This situation, which is always present in real machines, allows verification of nonlinear effects in the superposition. In order to emphasize the thermal effect, the deflection due to the mechanical load alone was subtracted. Only the position of external loads, which leads to open crack, has been considered.
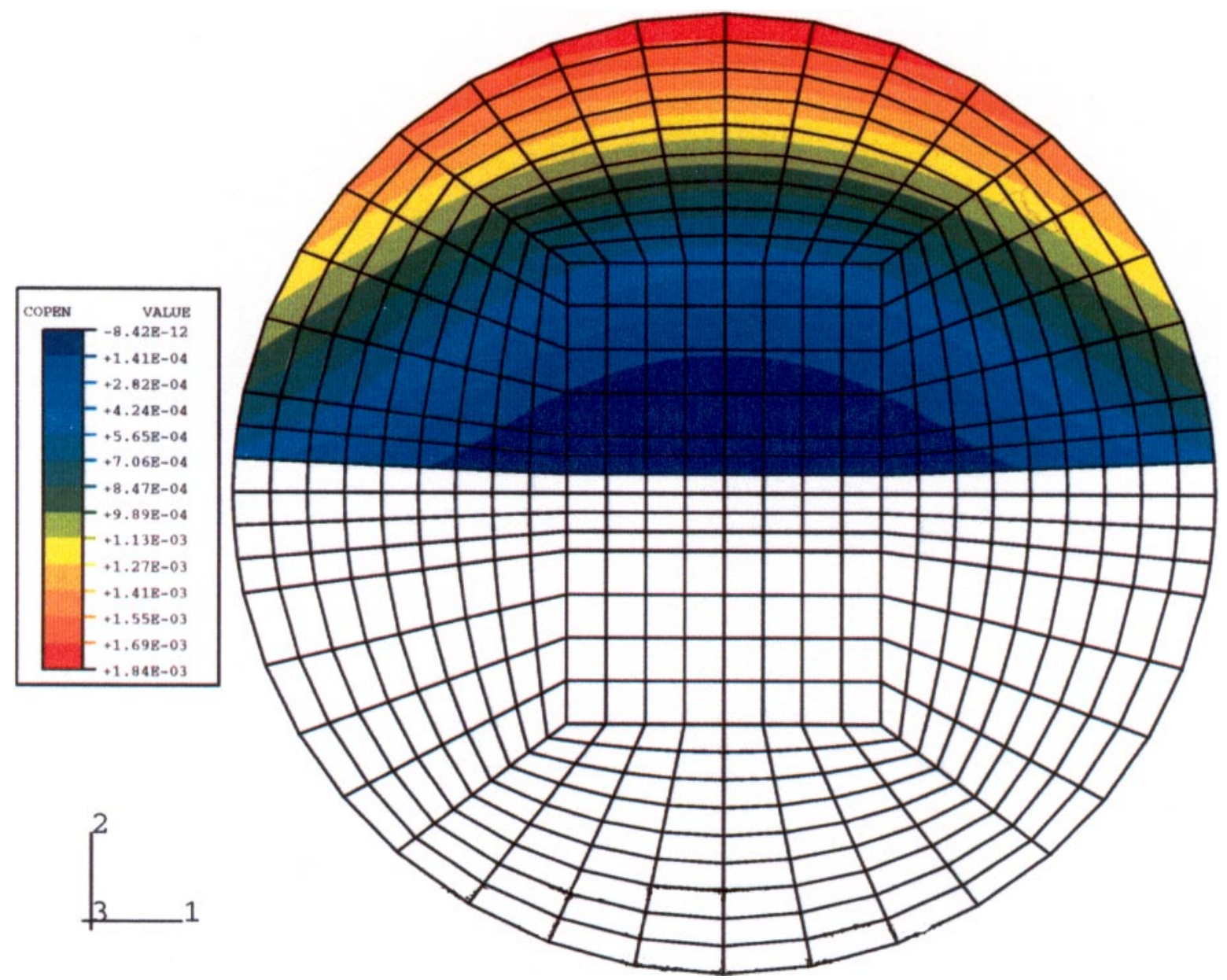

FIGURE 6

Relative axial displacements on the crack's surface. 


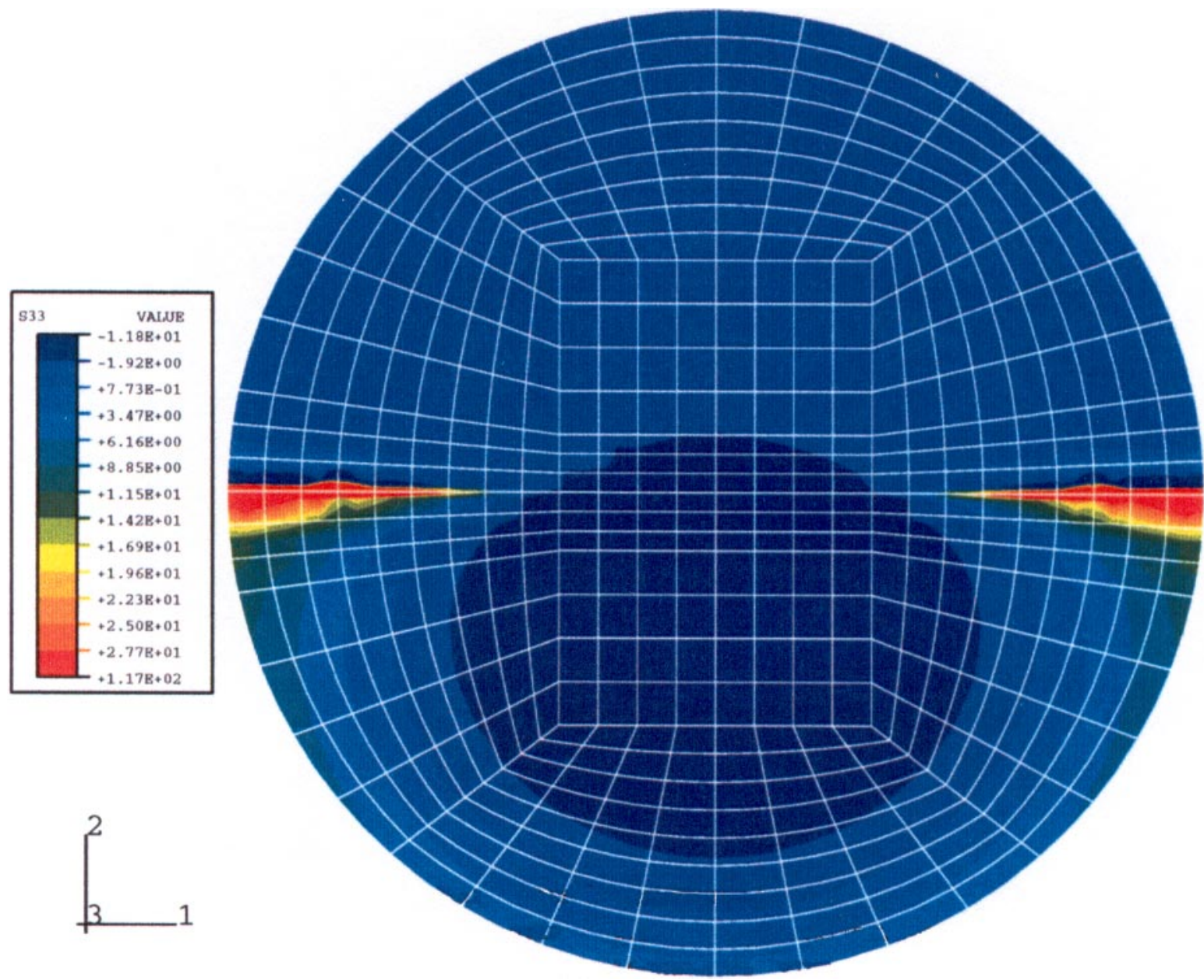

FIGURE 7

Axial stresses on the cracked section.

From the results of Table 1 the following conclusions can be drawn:

- The behaviors corresponding to equal and opposite temperature gradients are symmetrical.

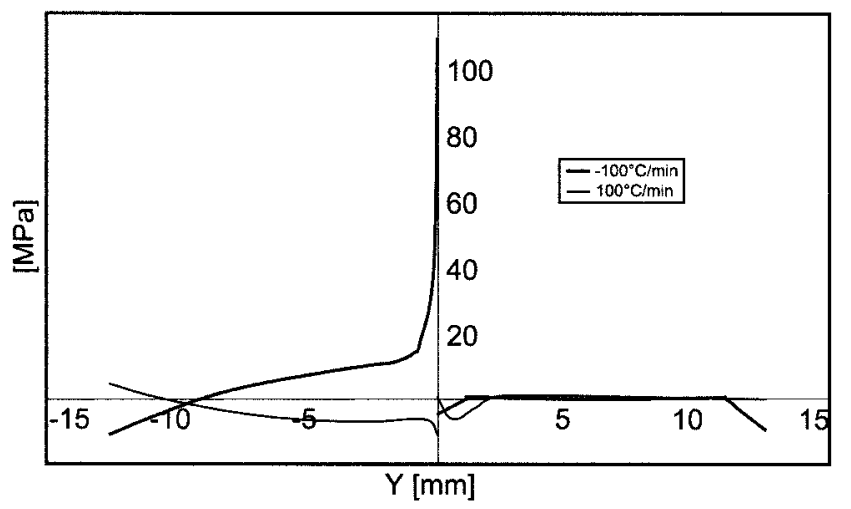

FIGURE 8

Stress distribution along the vertical diameter passing though the middle of the crack.
- The 1D linear model systematically underestimates the deflections for deeper cracks $(50 \%)$ and for smaller cracks $(25 \%)$ in cases of sharper temperature gradients.

- Because the errors introduced by the 1D linear model are between a minimum of $+0.7 \%$ and a maximum of $23 \%$, the results can be considered a rough estimate of the actual behavior.

Other simulations show that when the cracked beam is without mechanical loads, and is loaded only by thermal stresses, then the symmetry of behavior is lost. Negative gradients produce the same deflections, as shown in Table 1, but positive gradients produce only very little deflections.

Thermal transients are considered to be long when the heat is propagated to the whole body of the beam. As previously noted, completely different stress and strain distributions can be found with respect to short transients. The axial stress distribution over the cross-section of the beam, as obtained by the 1D model with the smoother thermal transient $\left( \pm 20^{\circ} \mathrm{C} / \mathrm{min}\right)$ after $15 \mathrm{~min}$, is very similar to that obtained for $\pm 100^{\circ} \mathrm{C} / \mathrm{min}$ gradient after $5 \mathrm{sec}$ (see Fig. 3). 
TABLE 1

Comparison of Deflections Due to Thermal Stresses in $\mu \mathrm{m}$

\begin{tabular}{lcccccccc}
\hline & \multicolumn{2}{c}{$+20^{\circ} \mathrm{C} / \mathrm{min}$} & \multicolumn{2}{c}{$-20^{\circ} \mathrm{C} / \mathrm{min}$} & \multicolumn{2}{c}{$+100^{\circ} \mathrm{C} / \mathrm{min}$} & \multicolumn{2}{c}{$-100^{\circ} \mathrm{C} / \mathrm{min}$} \\
\hline Model & 3D & $1 \mathrm{D}$ & $3 \mathrm{D}$ & $1 \mathrm{D}$ & $3 \mathrm{D}$ & $1 \mathrm{D}$ & $3 \mathrm{D}$ & $1 \mathrm{D}$ \\
$25 \%$ crack & +0.133 & +0.135 & -0.133 & -0.134 & +0.541 & +0.433 & -0.571 & -0.459 \\
$50 \%$ crack & +0.419 & +0.320 & -0.416 & -0.320 & +1.66 & +1.36 & +1.66 & -1.36 \\
\hline
\end{tabular}

Considering the $50 \%$ crack and the smoother thermal heating transient $\left(+20^{\circ} \mathrm{C} / \mathrm{min}\right)$ after $15 \mathrm{~min}$, the contact pressures shown in Figure 9 are obtained, to be compared with those in Figure 10, which are related to the same transient, but after $10 \mathrm{sec}$.

Dark blue indicates no contact pressure. If the mechanical external load is superposed, then higher compressive stresses arise in the middle of the beam (the distribution over the cracked surface is shown in Fig. 11). The behavior is therefore as would be expected.

\section{THE 1D MODEL OF THE CRACK}

The proposed crack model, briefly described, is as follows. The steps for modeling the breathing behavior, including thermal effects, are:
1. The bending moment $M$, due to the weight and the bearing alignment conditions of the rotor, is calculated in correspondence with the cracked section

2. One revolution of the shaft is divided into several parts. In each position, the following iterative calculations are performed on the discretized section shown in Figure 12 in order to define the open and closed sections of the cracked area, the position of the center of gravity $\mathrm{G}$ of the closed surface, the position of the main axis of inertia (angle $\vartheta$ ) with origin in $\mathrm{G}$, the second-area moments with respect to the main axis, and the moments $M_{B x}, M_{B y}$ due to the thermal stress distribution.

- Initially, the main axes $\left(x_{m}^{\prime}, y_{m}^{\prime}\right)$ are considered to be coincident with the rotating crack axes $(\vartheta=0)$; the

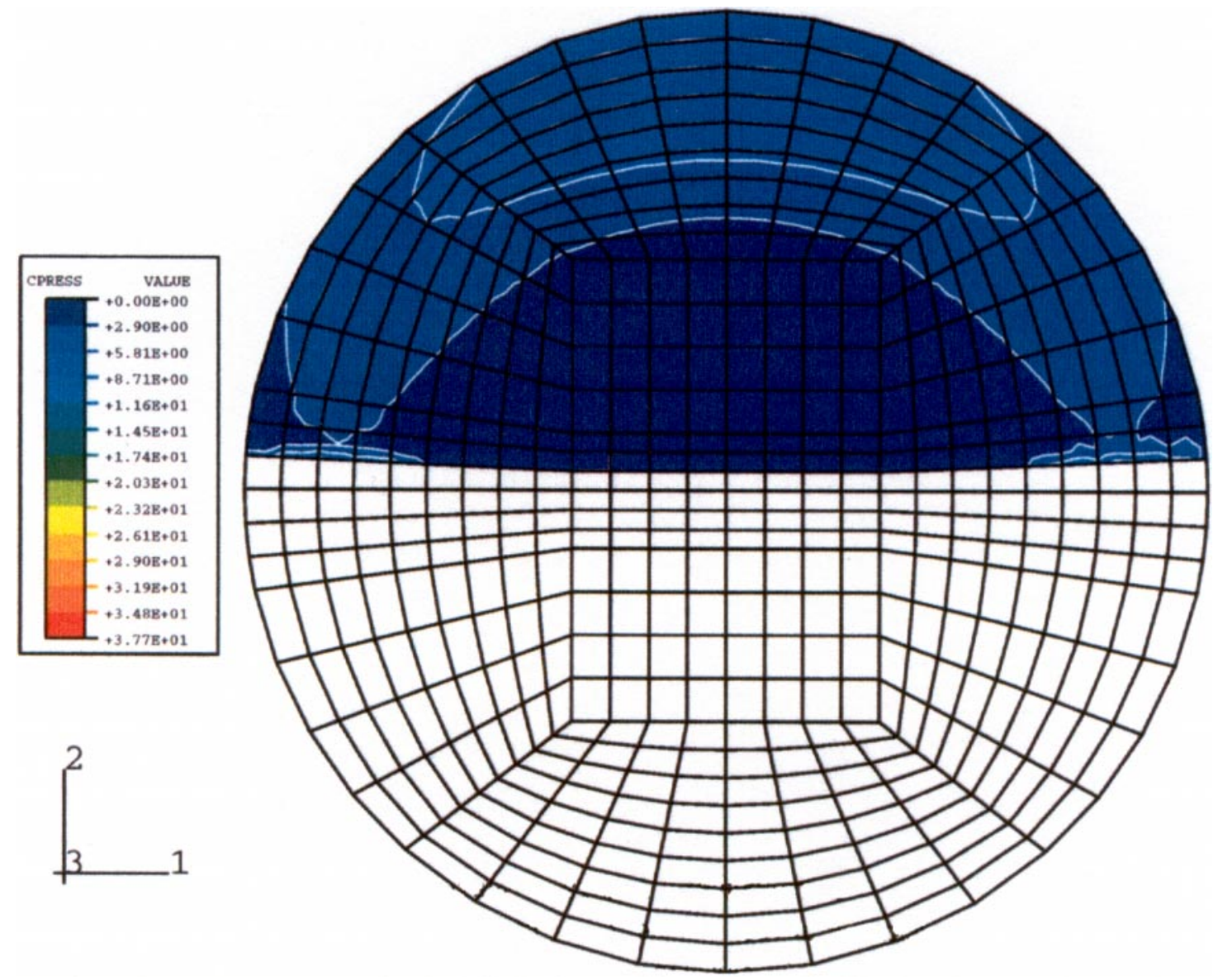

FIGURE 9

Contact pressure distribution, transient $+20^{\circ} \mathrm{C} / \mathrm{min}, 15 \mathrm{~min}$. 


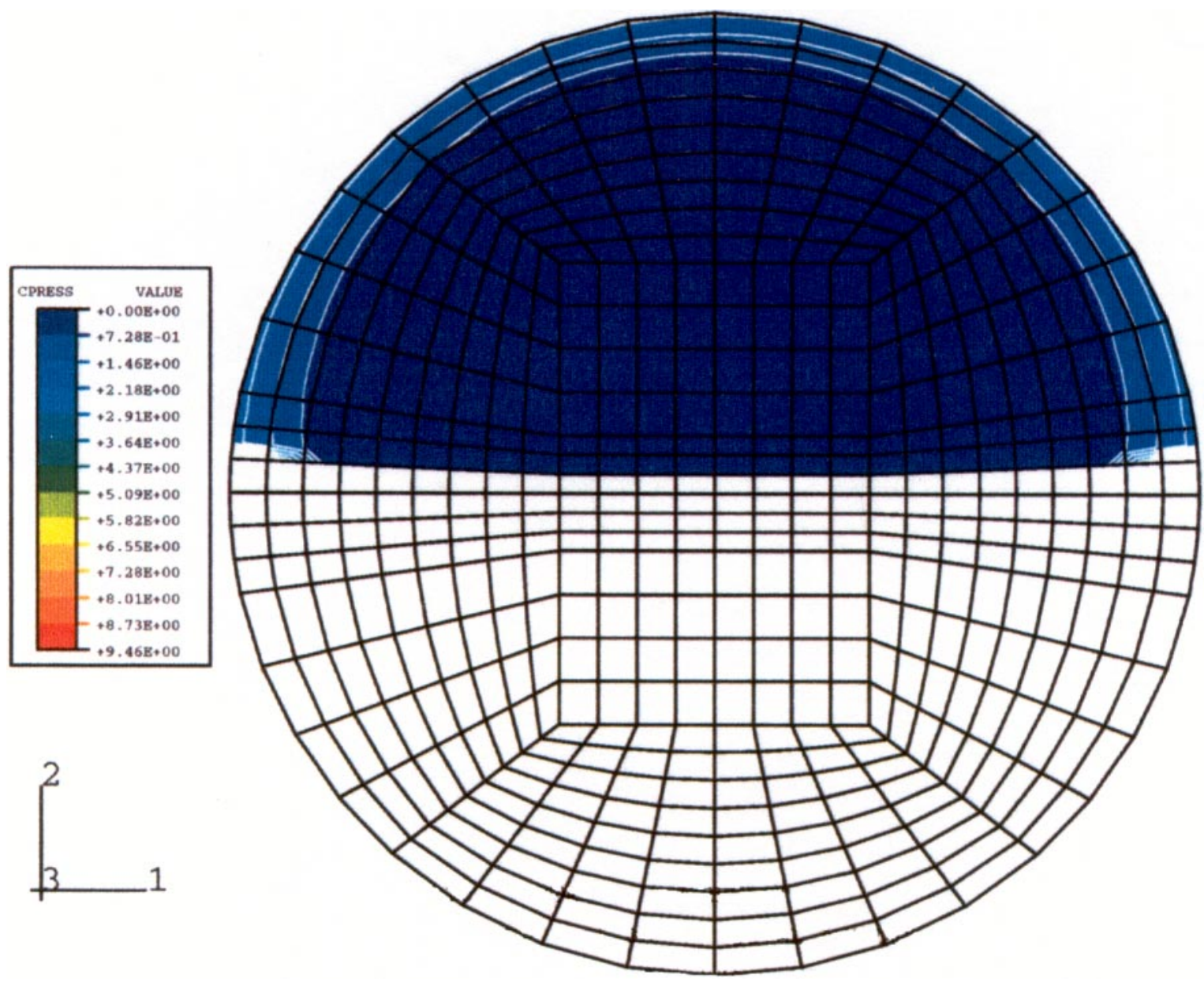

FIGURE 10

Contact pressure distribution, transient $+20^{\circ} \mathrm{C} / \mathrm{min}, 10 \mathrm{sec}$.

stresses due to bending moment are calculated (with the assumed $x^{\prime} y^{\prime}$ main axis), and the thermal stresses are then added in each point.

- Then the stress distribution is known over the crosssection, and the sign of the stress can be checked in each point of the cracked area: a plus sign means tension, and therefore there are no contact forces at this point (the crack area element is open); a minus sign means compression, and therefore there are contact forces (the crack area element is closed). The open and closed areas were determined.

- The surface gravity center of the total area (formed by the uncracked area plus the closed cracked area) can be calculated.

- The second moments of the area can then be calculated with respect to the reference system, with the origin in $\mathrm{G}$ and the angular position $\vartheta$, the main axis of inertia can be found.

- Then the procedure is repeated with the new value of $\vartheta$ until $\vartheta$ converges into a stable value.
3. At this point, the position of the main axis and the second moments of area $M_{B x}, M_{B y}$ are known. The second moment of area $J_{x}, J_{y}$, and $J_{x y}$, with respect to the fixed reference frame ( $x y)$, and the components of the moments due to the thermal stress distribution $\left(M_{x}, M_{y}\right)$, with respect to the same reference frame, are calculated. This is repeated for each angular position of the shaft.

The second moments of area, which are a function of the angular position, can then be used for calculating the stiffness $K_{c}(\Omega t)$ that is also a function of the angular position of the cracked beam element, which has a suitable length $l_{c}$. The moments of the thermal stress distribution are used for calculating the thermal bow.

\section{EQUIVALENT BEAM STIFFNESS MATRIX}

Once the breathing mechanism and the second moments of area have been defined for the various angular positions, the stiffness matrix of the cracked element of suitable length $l_{c}$ can be calculated, assuming a Timoshenko beam. 


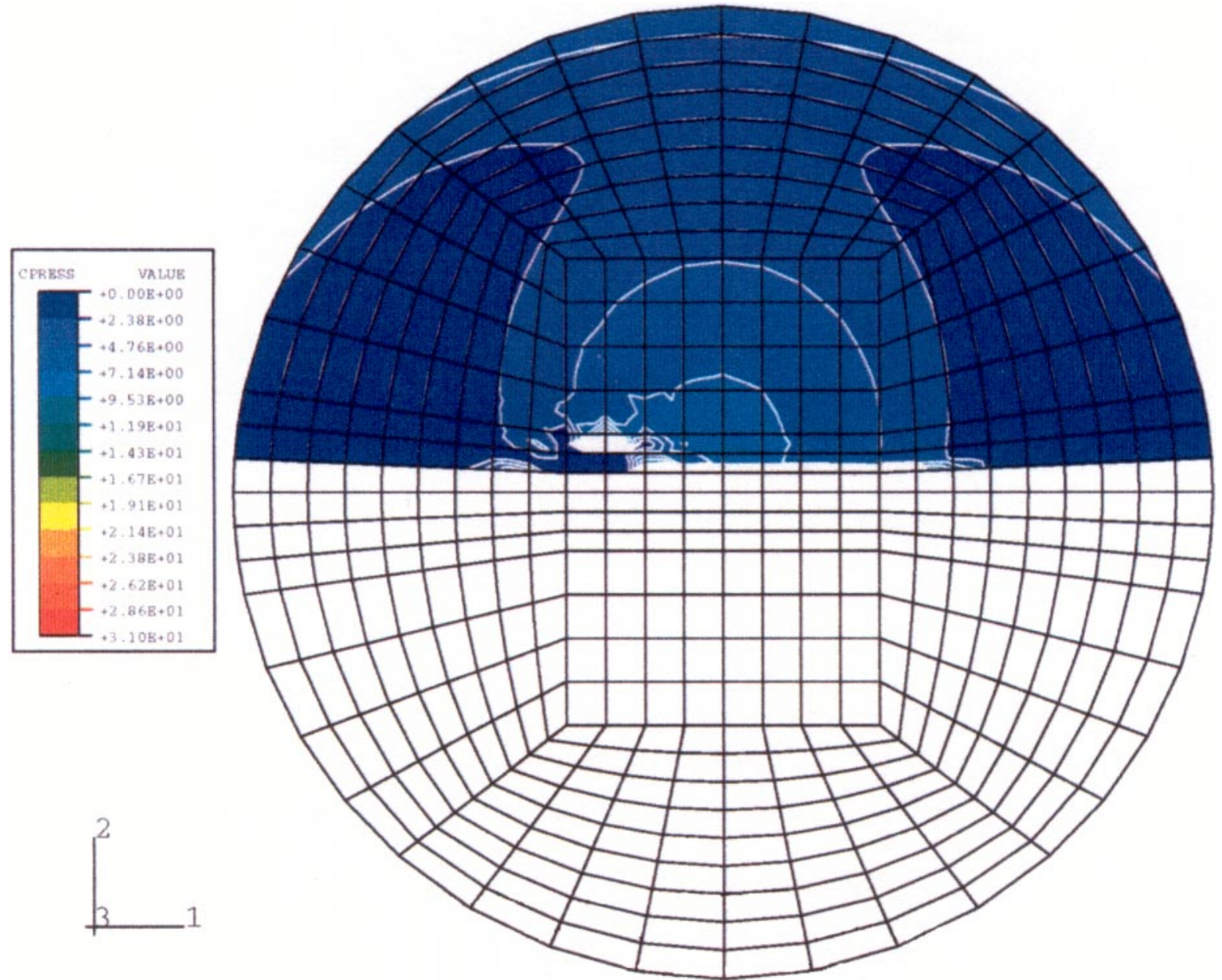

FIGURE 11

Contact pressure distribution over the cracked section, transient $+20^{\circ} \mathrm{C} / \mathrm{min}, 10 \mathrm{sec}$.

The stiffness matrix (square, symmetrical, $12 \times 12$ elements) where the coefficients are defined as follows: is represented by Equation (6):

$$
\begin{aligned}
& K_{c}(\Omega t)\left\{\begin{array}{l}
\mathbf{X}_{1} \\
\mathbf{X}_{2}
\end{array}\right\} \\
& =\left[\begin{array}{cccccccccccc}
a & c & p & q & w & m & -a & c & -p & q & -w & -m \\
& e & -q & r & i & 0 & -c & f & q & s & -i & 0 \\
b & -d & k & n & -p & -q & -b & -d & -k & -m \\
& h & j & 0 & -q & s & d & g & -j & 0 \\
& & t & 0 & -w & -i & -k & -j & -t & 0 \\
\vartheta_{y 1} \\
y_{1} \\
\vartheta_{x 1} \\
z_{1} \\
\vartheta_{z 1} \\
x_{2} \\
\vartheta_{y 2} \\
y_{2} \\
\vartheta_{x 2} \\
z_{2} \\
\vartheta_{z 2}
\end{array}\right\}
\end{aligned}
$$

$$
\begin{aligned}
& a=\frac{12 J_{y} E}{(1+\phi) l_{c}^{3}} \quad b=\frac{12 J_{x} E}{(1+\phi) l_{c}^{3}} \\
& c=\frac{6 J_{y} E}{(1+\phi) l_{c}^{2}} \quad d=\frac{6 J_{x} E}{(1+\phi) l_{c}^{2}} \\
& e=\frac{(4+\phi) J_{y} E}{(1+\phi) l_{c}} \quad f=\frac{(2-\phi) J_{y} E}{(1+\phi) l_{c}} \\
& g=\frac{(2-\phi) J_{x} E}{(1+\phi) l_{c}} \quad h=\frac{(4+\phi) J_{x} E}{(1+\phi) l_{c}} \\
& p=-\frac{12 J_{x y} E}{(1+\phi) l_{c}^{3}} \quad q=\frac{6 J_{x y} E}{(1+\phi) l_{c}^{2}} \\
& r=\frac{(4+\phi) J_{x y} E}{(1+\phi) l_{c}} \quad s=\frac{(2-\phi) J_{x y} E}{(1+\phi) l_{c}}
\end{aligned}
$$




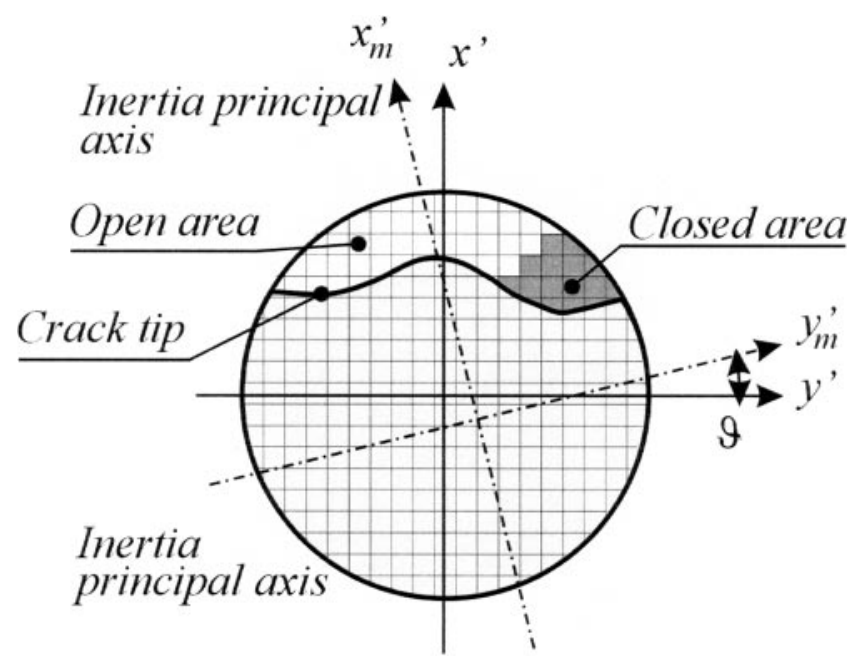

FIGURE 12

Cracked cross-section.

$$
\begin{aligned}
& t=\frac{E A}{l_{a}} \quad u=\frac{G J_{p}}{l_{t}} \\
& w=t^{*} X_{g}^{*} c_{3} \quad k=-t^{*} Y_{g}^{*} c_{3} \\
& m=a^{*} Y_{g T}{ }^{*} c_{1} \quad n=b^{*} X_{g T}{ }^{*} c_{1} \\
& i=t^{*} X_{g}{ }^{*} c_{2} \quad j=t^{*} Y_{g}{ }^{*} c_{2}
\end{aligned}
$$
by

The parameter $\phi$ accounts for the shear effects and is given

$$
\phi=\frac{12 E J}{G S l_{c}^{2}} .
$$

$E$ and $G$, respectively, are the Young's modulus and the shear modulus; $S$ is the cross-section area. The various lengths $l_{c}, l_{a}$, and $l_{t}$, which are responsible for the direct stiffnesses, and the parameters $c_{1}, c_{2}$, and $c_{3}$, which are responsible for the cross-coupling terms, were tuned by means of the $3 \mathrm{D}$ model.

The lengths $l_{c}, l_{a}$, and $l_{t}$ represent the extent to which the crack exerts its influence. The lengths are obviously related to the depth of the crack, as shown in Figure 13, where the relative length (the ratio of length $l_{c}$ to diameter) is represented as a function of the relative depth (the ratio of depth to diameter). The cracked element can then be introduced into the original beam element of length $l$. If length $l$ is greater than the maximum value among $l_{c}, l_{a}$, and $l_{t}$, the stiffness of the element is easily calculated as is its deflection due to external loads in the various angular positions. If, on the contrary, the original element is shorter than the same maximum value, some additional processing of $K_{c}(\Omega t)$ is required, as shown below.

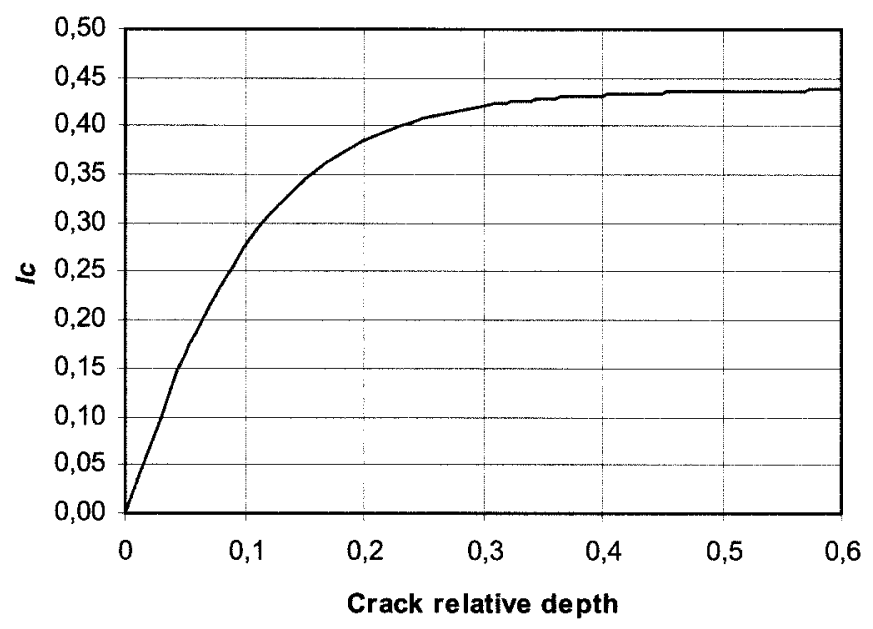

FIGURE 13

Equivalent length $l_{c}$ of the cracked beam.

\section{DERIVATION OF LOCAL CRACK STIFFNESS}

The rotation-dependent stiffness matrix $K_{c}$ of a cracked beam element of length $l$ (Fig. 14A) can be split into a stiffness matrix with three different parts: the stiffness of two equal uncracked beams of length $l / 2$ combined with a "local" stiffness part composed of "springs" that represent the crack (Fig. 14B).

These springs have an infinite stiffness when the crack is closed and a finite stiffness when the crack is open. To extract the local stiffness due to the crack from the total stiffness, it's necessary to introduce two additional nodes, $\mathrm{L}$ and $\mathrm{R}$, which represent, respectively, the left and right sides of the crack faces.

Denoting by 1 the initial node of the cracked beam element, by 2 its final node, and by $\mathbf{X}_{1}$ and $\mathbf{X}_{2}$ the vectors of the displacements of nodes 1 and 2 , respectively, $K_{c}$ can be considered a $12 \times 12$

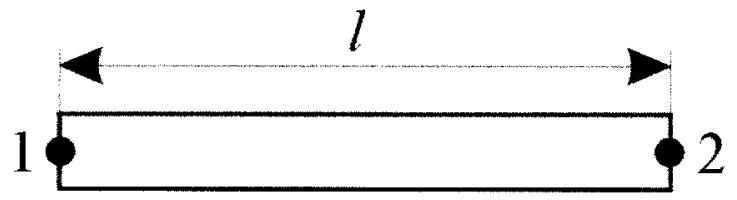

(A)

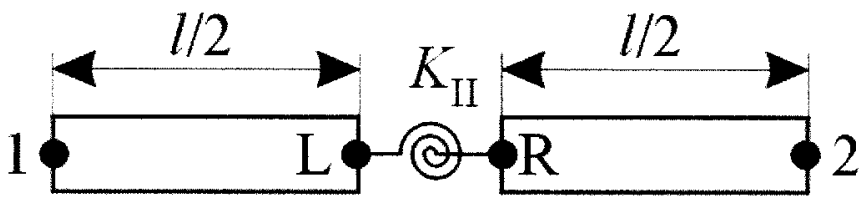

(B)

FIGURE 14

Cracked beam. 
matrix that leads to the following equation:

$$
\left[K_{c}\right]\left\{\begin{array}{l}
\mathbf{X}_{1} \\
\mathbf{X}_{2}
\end{array}\right\}=\left[\begin{array}{l}
{\left[K_{11}\right]\left[K_{12}\right]} \\
{\left[K_{21}\right]\left[K_{22}\right]}
\end{array}\right]\left\{\begin{array}{l}
\mathbf{X}_{1} \\
\mathbf{X}_{2}
\end{array}\right\}=\left\{\begin{array}{l}
\mathbf{F}_{1} \\
\mathbf{F}_{2}
\end{array}\right\}
$$

where $\mathbf{F}_{1}$ and $\mathbf{F}_{2}$ represent the force vectors applied to the end nodes of the beam. This matrix, being 1 and 2 external nodes of the beam, has to be distinguished from local crack stiffness $K_{\mathrm{II}}$ (Fig. 14B) corresponding to nodes $\mathrm{L}$ and $\mathrm{R}$ of the crack face:

$$
\left[K_{\mathrm{II}}\right]=\left[\begin{array}{l}
{\left[K_{\mathrm{LL}}\right]\left[K_{\mathrm{LR}}\right]} \\
{\left[K_{\mathrm{LR}}\right]\left[K_{\mathrm{RR}}\right]}
\end{array}\right]
$$
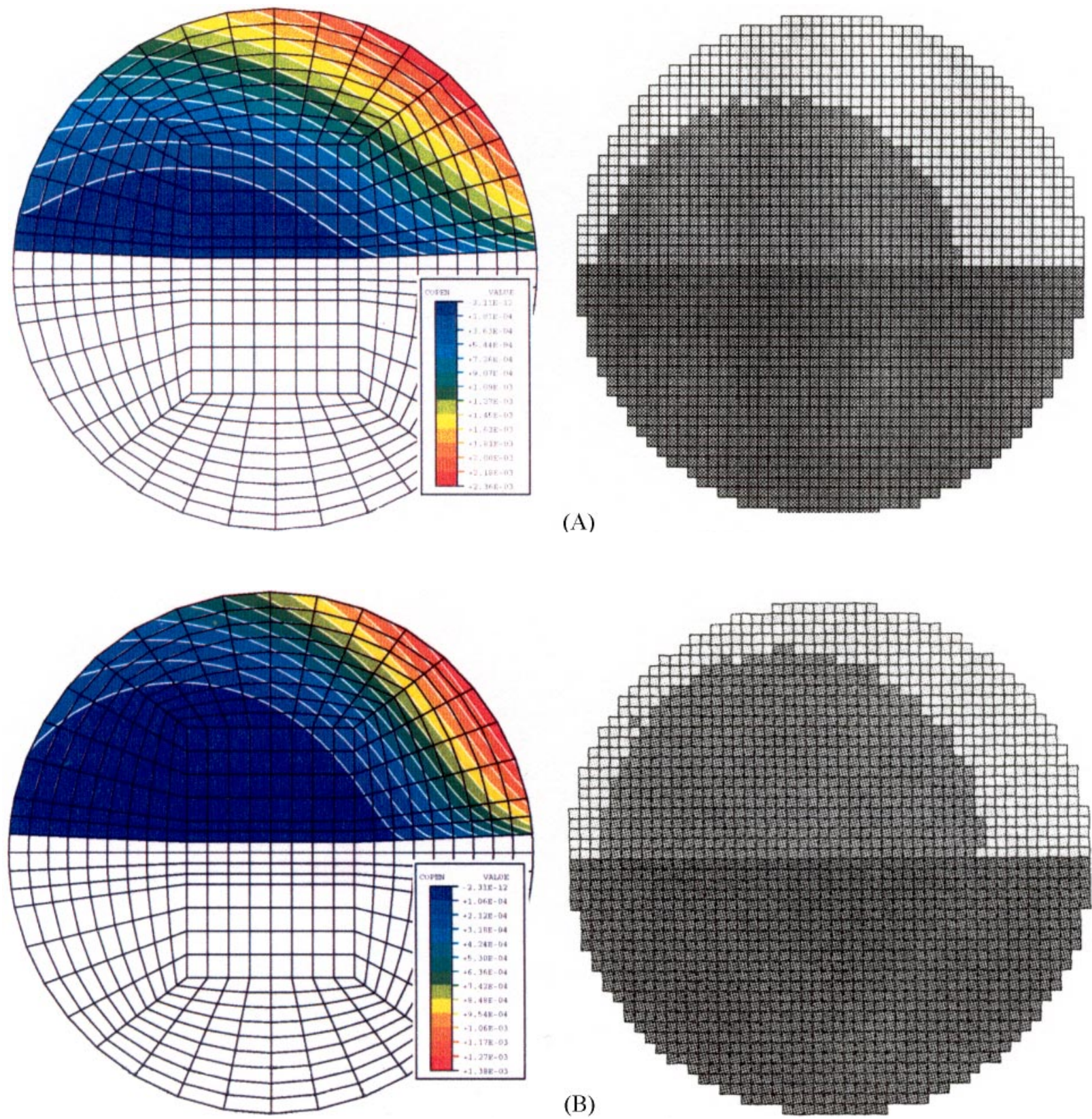

(A)

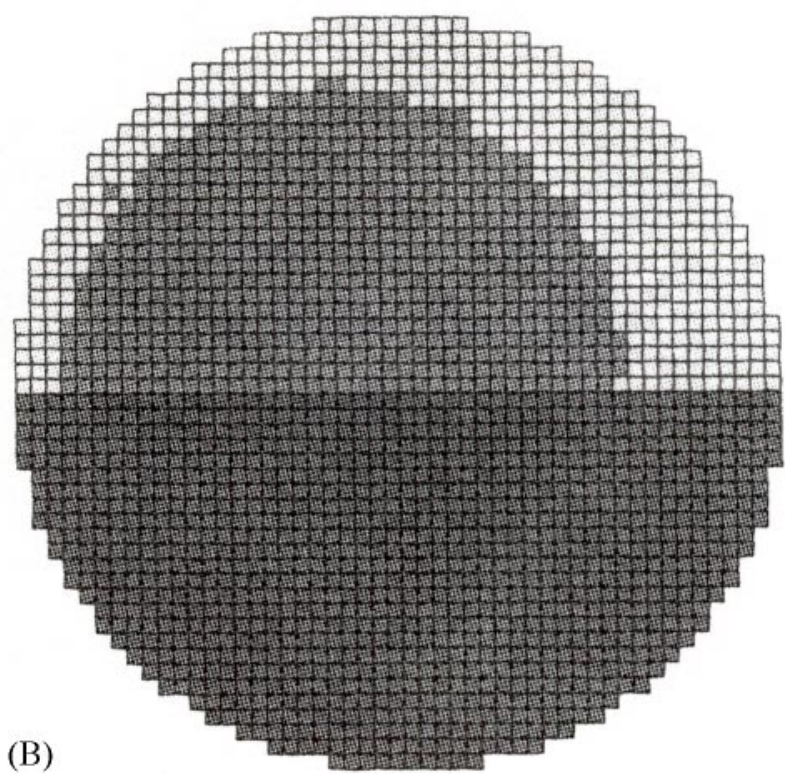

FIGURE 15

(A) A 50\%-depth crack after a 5-sec temperature transient on the outer surface of $-100^{\circ} \mathrm{C} / \mathrm{min}$, with external loads, at a 90-degree angle. (B) A 50\%-depth crack after a 5-sec temperature transient on the outer surface of $-100^{\circ} \mathrm{C} / \mathrm{min}$, with external loads, at a120-degree angle. (Continued) 

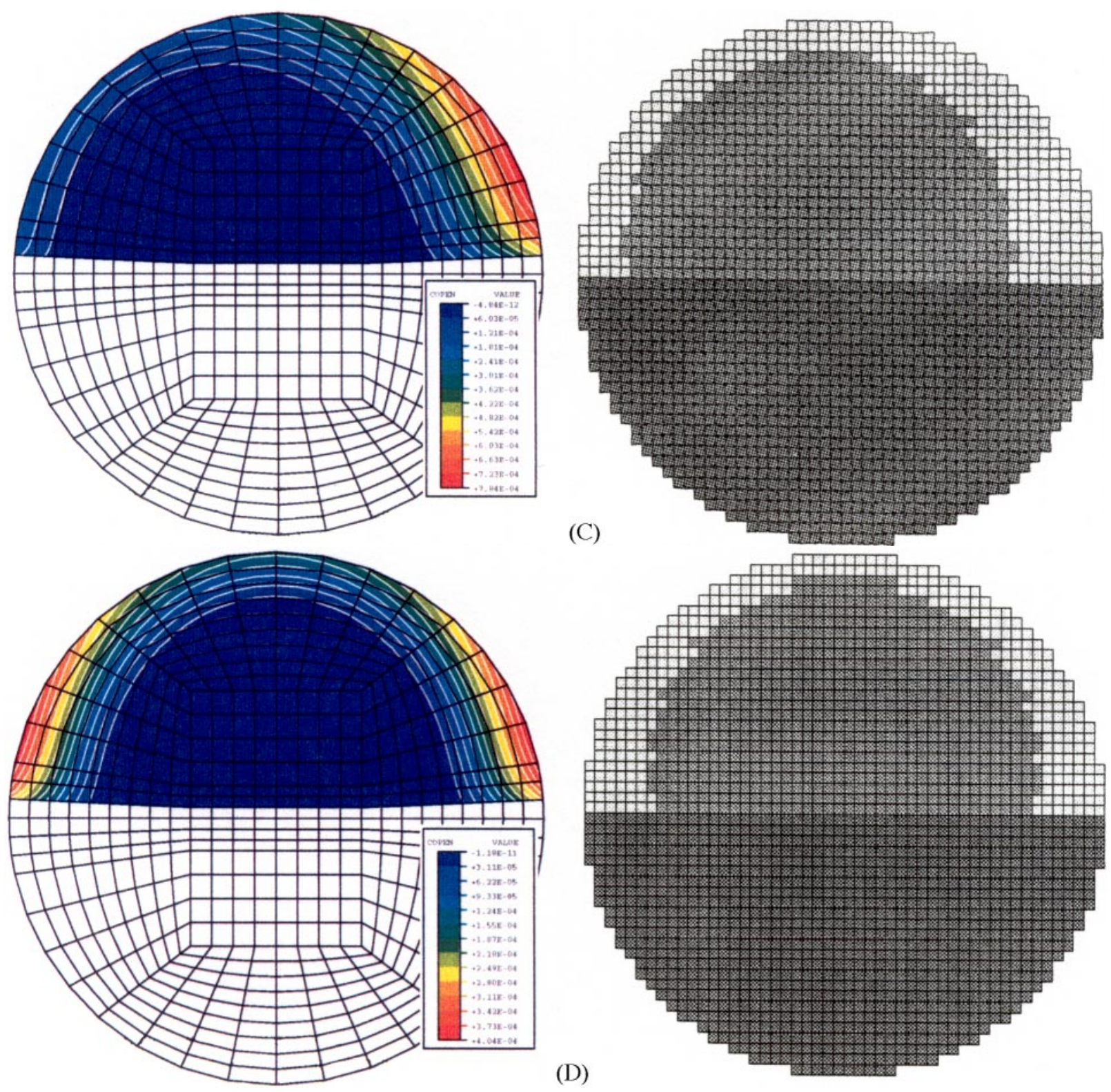

FIGURE 15

(Continued) (C) 50\%-depth crack after a 5-sec temperature transient on the outer surface of $-100^{\circ} \mathrm{C} / \mathrm{min}$, with external loads, at a 150-degree angle. (D) A 50\% depth crack after a 5-sec temperature transient on the outer surface of $-100^{\circ} \mathrm{C} / \mathrm{min}$, with external loads, at a 180-degree angle.

Considering the stiffness matrix according to Figure 14B, the following structure is produced:

$$
\left[\begin{array}{c||cc||c}
{\left[K_{11}\right]} & {\left[K_{1 \mathrm{~L}}\right]} & {\left[K_{1 \mathrm{R}}\right]} & {\left[K_{12}\right]} \\
\hline\left[K_{\mathrm{L} 1}\right] & {\left[K_{\mathrm{LL}}\right]} & {\left[K_{\mathrm{LR}}\right]} & {\left[K_{\mathrm{L} 2}\right]} \\
{\left[K_{\mathrm{R} 1}\right]} & {\left[K_{\mathrm{RL}}\right]} & {\left[K_{\mathrm{RR}}\right]} & {\left[K_{\mathrm{R} 2}\right]} \\
\hline\left[K_{21}\right] & {\left[K_{2 \mathrm{~L}}\right]} & {\left[K_{2 \mathrm{R}}\right]} & {\left[K_{22}\right]}
\end{array}\right]\left\{\begin{array}{l}
\mathbf{X}_{1} \\
\mathbf{X}_{\mathrm{L}} \\
\mathbf{X}_{\mathrm{R}} \\
\mathbf{X}_{2}
\end{array}\right\}=\left\{\begin{array}{c}
\mathbf{F}_{1} \\
0 \\
0 \\
\mathbf{F}_{2}
\end{array}\right\} .
$$

This matrix can be reordered considering the external (E) and internal (I) degrees of freedom of the beam element. Calling

$$
\left\{\begin{array}{l}
\mathbf{X}_{1} \\
\mathbf{X}_{2}
\end{array}\right\}=\mathbf{X}_{\mathrm{E}}, \quad\left\{\begin{array}{l}
\mathbf{X}_{\mathrm{L}} \\
\mathbf{X}_{\mathrm{R}}
\end{array}\right\}=\mathbf{X}_{\mathrm{I}}, \quad\left\{\begin{array}{l}
\mathbf{F}_{1} \\
\mathbf{F}_{2}
\end{array}\right\}=\mathbf{F}_{\mathrm{E}}
$$

leads to

$$
\left[\begin{array}{l}
{\left[K_{\mathrm{EE}}\right]\left[K_{\mathrm{EI}}\right]} \\
{\left[K_{\mathrm{IE}}\right]\left[K_{\mathrm{II}}\right]}
\end{array}\right]\left\{\begin{array}{c}
\mathbf{X}_{\mathrm{E}} \\
\mathbf{X}_{\mathrm{I}}
\end{array}\right\}=\left\{\begin{array}{c}
\mathbf{F}_{\mathrm{E}} \\
0
\end{array}\right\}
$$


where $K_{\mathrm{EI}}$ and $K_{\mathrm{IE}}$ are the stiffness matrixes of the uncracked beam elements of length $l / 2$. Therefore, $K_{\mathrm{II}}$ can be extracted according to the following procedure, combining Equations (13) with Equation (17):

$$
\begin{aligned}
K_{c} \mathbf{X}_{\mathrm{E}} & =\mathbf{F}_{\mathrm{E}} \\
K_{\mathrm{EE}} \mathbf{X}_{\mathrm{E}}+K_{\mathrm{EI}} \mathbf{X}_{\mathrm{I}} & =\mathbf{F}_{\mathrm{E}} \\
K_{\mathrm{IE}} \mathbf{X}_{\mathrm{E}}+K_{\mathrm{II}} \mathbf{X}_{\mathrm{I}} & =0 \\
\mathbf{X}_{\mathrm{I}} & =K_{\mathrm{II}}^{-1}\left(-K_{\mathrm{IE}} \mathbf{X}_{\mathrm{E}}\right) \\
{\left[K_{\mathrm{EE}}-K_{\mathrm{EI}}\left(K_{\mathrm{II}}^{-1} K_{\mathrm{IE}}\right)\right] \mathbf{X}_{\mathrm{E}} } & =K_{c} \mathbf{X}_{\mathrm{E}}
\end{aligned}
$$

from which $K_{\mathrm{II}}$ is extracted:

$$
K_{\mathrm{II}}=\left[K_{\mathrm{EI}}^{-1}\left(K_{\mathrm{EE}}-K_{c}\right) K_{\mathrm{IE}}^{-1}\right]^{-1}
$$

It is interesting to note that the resulting local stiffness matrix $\mathrm{K}_{\mathrm{II}}$ does not show coupling terms between rotations and deflections, which instead exist in matrix $K_{c}$. This result was expected, considering that the local stiffnesses refer to a "beam" with zero length.

The local stiffness matrix can then be introduced into the cracked beam element removing any restriction about the length of the element. The bow, which has been calculated with the equivalent-length $l_{c}$ beam, generates a relative angular deflection of the end nodes; the same relative angular deflection can be applied directly to the crack faces in the local crack model.

\section{VALIDATION OF THE BREATHING MECHANISM MODEL BY TEMPERATURE GRADIENTS}

Positive and negative gradients and their effects on $25 \%$ and 50\%-depth cracks were considered. Because the dimensions of the model are small, and the maximum statical bending stress reaches $6.5 \mathrm{~N} / \mathrm{mm}^{2}$, a rather robust thermal transient was applied in order to generate stresses of the same order of magnitude.

Constant gradients of $\pm 100^{\circ} \mathrm{C} / \mathrm{min}$ and $\pm 20^{\circ} \mathrm{C} / \mathrm{min}$ were applied to the external surface of the cylinder, and the resulting stresses and breathing behavior were calculated after $5 \mathrm{sec}$ and $10 \mathrm{sec}$, respectively.

If the external load (bending plus torsion) is superposed onto the thermal load, the following figures are obtained for the $50 \%$-depth crack and the sharper temperature transient $\left(-100^{\circ} \mathrm{C} / \mathrm{min}\right.$ after $\left.5 \mathrm{sec}\right)$ : Figure 15 shows the situation corresponding to the following angular positions: $90,120,150$, and 180 degrees.

For smaller angles, the crack is completely open; for angles between 180 and 360 degrees; a symmetrical behavior is found, as expected. Similar results are obtained for other crack depths and other thermal transients. Note that the dark blue zones indicate zones in which contact between the crack faces occurs.

Although the agreement is not as good as it is in the case of simple mechanical loading, it can be considered satisfactory, bearing in mind that the actual stress distribution over the cracked section deviates strongly from the superposition of stresses used by the simplified linear model.

\section{CONCLUSION}

The thermal behavior of cracked round beams was analyzed by means of a 3D nonlinear model. The temperature distribution was unaffected by the crack, but the stress and strain distributions were strongly influenced by the crack. This resulted in a bow of the beam.

A 1D model for calculating temperature and axial stress distributions in an infinite cylinder was presented, and the results of the axial stress distribution were used to calculate thermal bows by means of a rough approximation. The acceptable level of agreement with results obtained by means of the 3D nonlinear model validated the proposed procedure.

Further, a 1D model of a crack was described; it allowed cracks of various shapes to be modeled and thermal stresses to

\begin{tabular}{|c|c|}
\hline$c_{1}, c_{2}, c_{3}$ & $\begin{array}{l}\text { cross-coupling stiffness coefficient tuning } \\
\text { parameters }\end{array}$ \\
\hline$c_{p}$ & specific heat \\
\hline$E$ & Young's modulus \\
\hline $\mathbf{F}$ & force vector \\
\hline$G$ & shear modulus \\
\hline$H$ & thermal exchange coefficient \\
\hline$J_{x}, J_{y,} J_{x y}$ & second moments of area \\
\hline$k$ & conduction coefficient \\
\hline$K$ & stiffness matrix \\
\hline$K_{c}$ & stiffness matrix of cracked beam element \\
\hline$l$ & beam length \\
\hline$l_{a}$ & equivalent length for the axial stiffness \\
\hline$l_{c}$ & $\begin{array}{l}\text { length of the equivalent beam used to model the } \\
\text { crack }\end{array}$ \\
\hline$l_{t}$ & equivalent length for the torsional stiffness \\
\hline$M$ & $\begin{array}{l}\text { bending moments due to the weight and the bearing } \\
\text { alignment conditions of the rotor }\end{array}$ \\
\hline$M_{x}, M_{y}$ & $\begin{array}{l}\text { bending moments due to thermal stress distribution, } \\
\text { with respect to the fixed reference }\end{array}$ \\
\hline$M_{B x}, M_{B y}$ & $\begin{array}{l}\text { bending moments due to thermal stress distribution, } \\
\text { with respect to the main axes }\end{array}$ \\
\hline$r$ & radial coordinate \\
\hline$T$ & temperature \\
\hline
\end{tabular}
be taken into account. The breathing mechanism obtained with this $1 \mathrm{D}$ model was validated by $3 \mathrm{D}$ nonlinear calculations. The good agreement obtained allows proposal of the 1D model as a powerful tool for analyzing cracked rotors.

\section{NOMENCLATURE}


$T_{m} \quad$ average section temperature

$T_{\text {rest }} \quad$ temperature of the external surface

$T_{w} \quad$ fluid temperature

$x, y \quad$ fixed reference frame

$x^{\prime}, y^{\prime} \quad$ reference system fixed on the rotor

$x_{m}^{\prime}, y_{m}^{\prime} \quad$ main axes

$\mathbf{X}$ displacement vector

$X_{g}, Y_{g} \quad$ coordinates of the center of the area of the section

$X_{g T}, Y_{g T} \quad$ coordinates of the center of the area of the section that participates in the torsion

$\alpha \quad$ linear thermal expansion

$\vartheta \quad$ angular position of main axis of inertia

$v \quad$ Poisson's coefficient

$\phi \quad$ parameter of the shear effect

$\rho \quad$ density

$\sigma \quad$ axial stress

\section{REFERENCES}

Bachschmid, N., Vania, A., and Audebert, S. 2000, March. A comparison of different methods for transverse crack modeling in rotor system, 1057-1064. Proceedings of The ISROMAC-8 Conference. Honolulu, HI: Texas A\&M University.

Dimarogonas, A. D. 1996. Vibration of cracked structures: a state-ofthe-art review. Engineering Fracture Mechanics 55:831-857.

Gasch, R., 1993. A survey of the dynamic behavior of a simple rotating shaft with a transverse crack. Journal of Sound and Vibration 160:313-332.

Lapini, G. L., Zippo, M., Bachschmid, N., Collina, A., and Vallini, A. 1993. Experimental tests and model-based calculations for the diagnosis of a crack in a 320 MW generator. In G. Diana, ed., Diagnostics of Rotating Machines in Power Plants, 321-328. New York: Springer-Verlag.

Wauer, J. 1990. On the dynamics of cracked rotors: a literature survey. Applied Mechanics Review 3:13-17. 

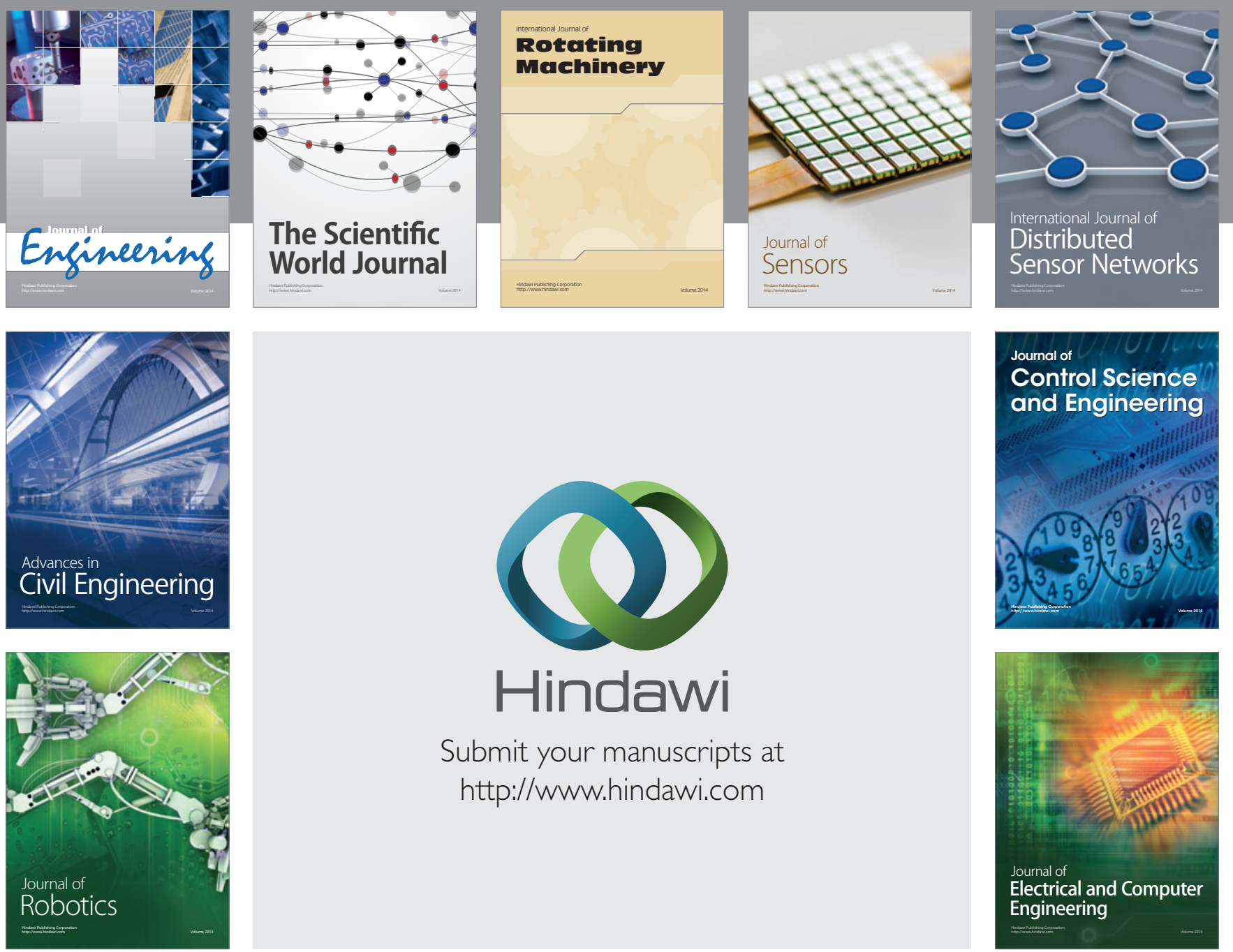

Submit your manuscripts at

http://www.hindawi.com
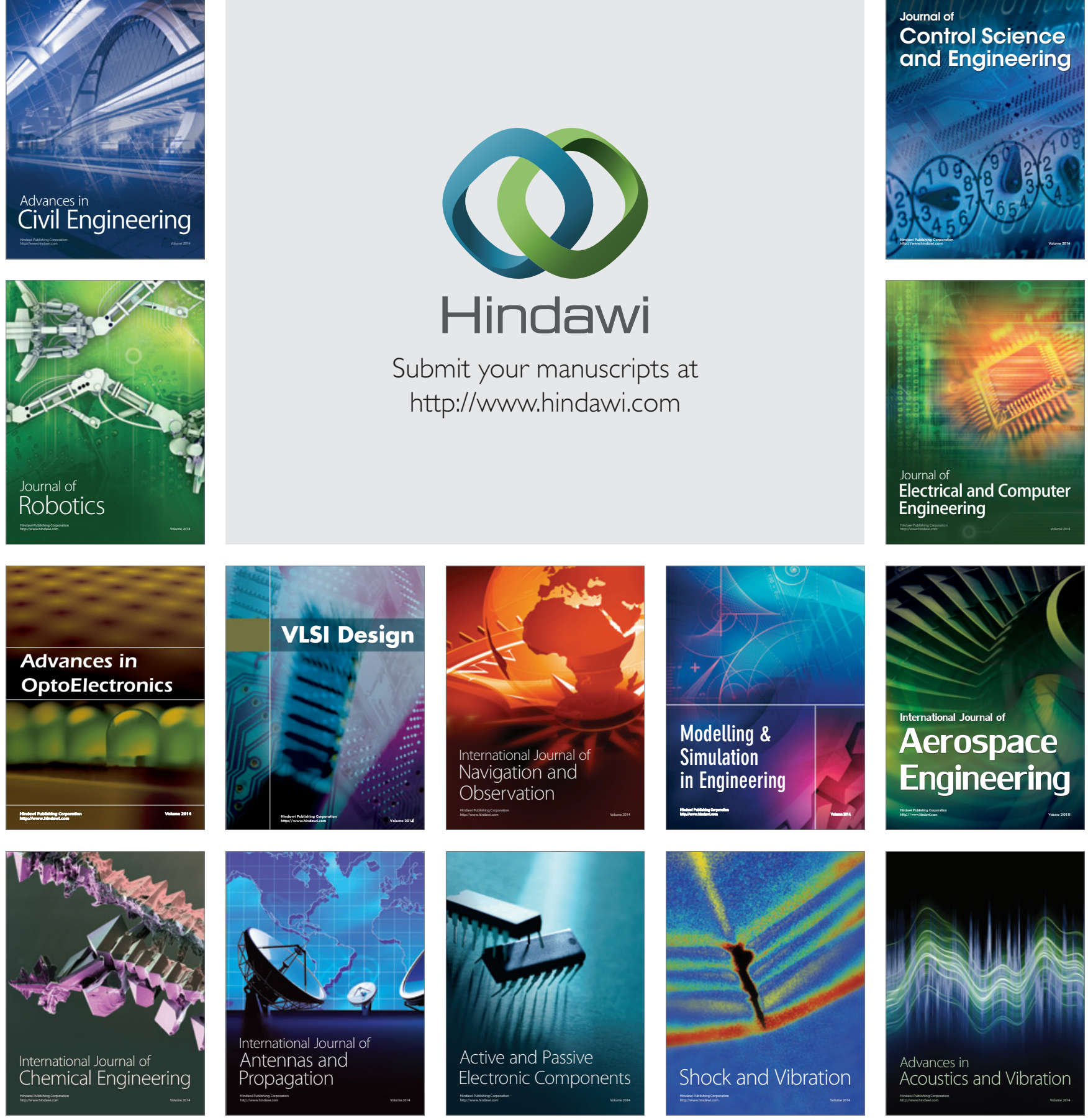